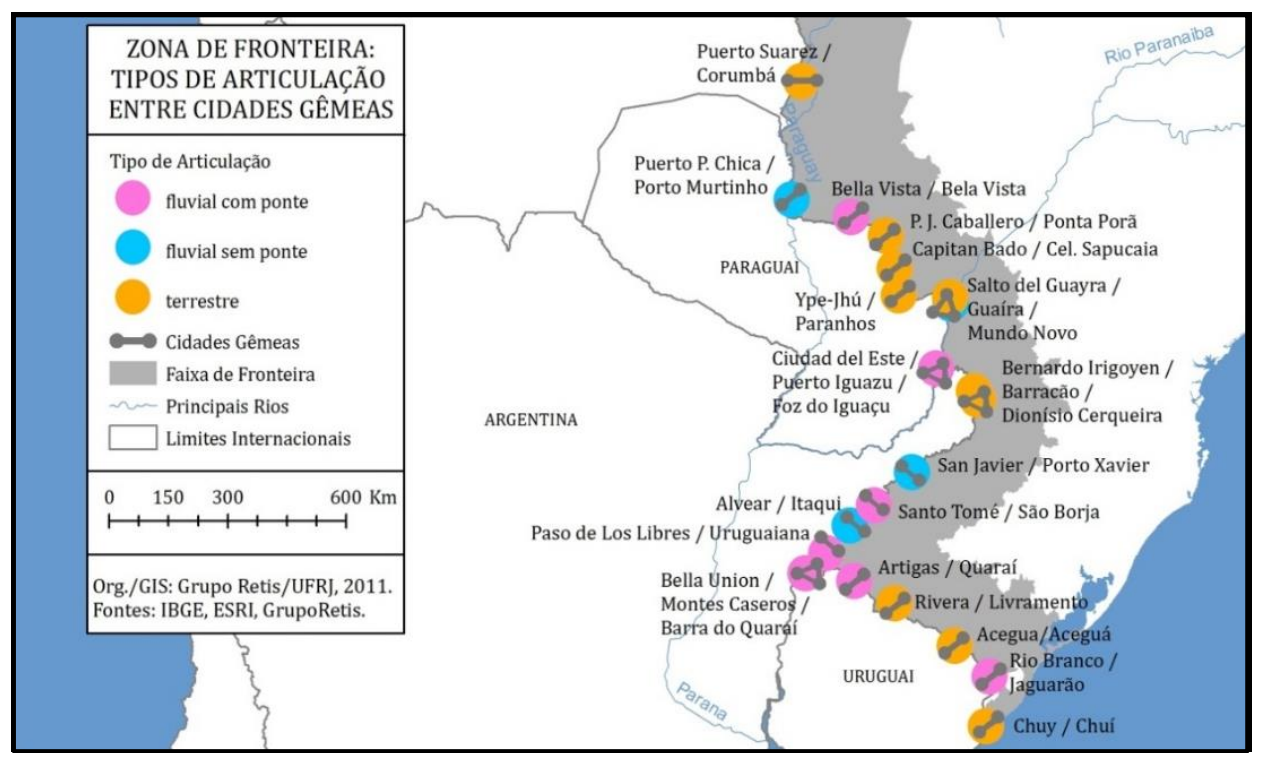

\title{
Política de línguas, circulação de jornais e integração em cidades-gêmeas da fronteira.
}

\author{
Language policies, newspaper circulation and integration \\ in twin-cities from border.
}

\begin{abstract}
Andréa F. Weber ${ }^{1}$
Resumo: Neste artigo, analisamos os sentidos políticos inscritos no uso das línguas por jornais locais, a partir de sua circulação nas cidades-gêmeas da fronteira platina e do conceito de integração transfronteiriça. Apresentamos dados sobre a abrangência e os usos linguísticos de 17 jornais brasileiros, de 20 cidades-gêmeas, dos anos de 2010 a 2014. Interpretamo-los à luz de estudos sobre Política de Línguas, Mídia e Fronteiras, como os de Orlandi (2002), Guimarães (2003, 2005), Sturza (2005, 2006), Peruzzo (2003) e Machado (2009). Identificamos que a língua espanhola e a abrangência transfronteiriça estão presentes em menos da metade das publicações e que ocorre, em geral, uma sobreposição entre língua nacional, nação e área de circulação do jornal.
\end{abstract}

Palavras-chave: Política de Línguas, jornais; fronteira; integração.

Abstract: In this article, we analyze the political meanings inscribed in the use of languages by local newspapers, based on their circulation in the twin-cities from the platinum border and on the concept of transborder integration. We present data about the coverage and the linguistic uses in 17 brazilian newspapers, from 20 twin-cities, in the period between 2010 and 2014. We interpret these data based on studies about Language Policies, Media and Borders, as those by Orlandi (2002), Guimarães (2003, 2005), Sturza (2005, 2006), Peruzzo (2003) and Machado (2009). We have identified that the Spanish language and the transborder coverage are present in less than a half of the publications and that, in general, there is an overlapping among national language, nation and the newspaper circulation area.

Keywords: Language Policies; newspapers; border; integration.

\footnotetext{
${ }^{1}$ Doutora em Letras/Linguística. Professora Adjunta do Departamento de Ciências da Comunicação da Universidade Federal de Santa Maria, campus Frederico Westphalen. Endereço profissional: Linha sete de Setembro, s/n, BR 386, Campus da UFSM, Bloco 1, sala 307. Frederico Westphalen, RS, CEP 98400000. Endereços eletrônicos: andrea.weber@ufsm.br; af_weber@yahoo.com.br.
} 


\section{Introdução.}

Este artigo busca interpretar os sentidos políticos inscritos no uso das línguas por jornais fronteiriços, associando-as à sua circulação nas cidades geminadas da fronteira platina e à ideia de integração transfronteiriça. Cidades-gêmeas são definidas pelo Ministério da Integração Nacional brasileiro como localidades fronteiriças vinculadas, cidades contíguas, adensamentos populacionais cortados pela linha divisória internacional (BRASIL, 2005). Na fronteira platina, aqui operacionalizada como os limites de Brasil com Paraguai, Argentina e Uruguai, encontramos 20 cidades nessas condições, algumas articuladas por fronteiras terrestres (dez), outras por pontes (sete) e outras por balsas (três) ${ }^{2}$.

As cidades-gêmeas da fronteira são aquelas que apresentam maior nível de integração entre si e são conectores estratégicos da integração no Mercosul (BRASIL, 2005). Quando tratamos de fronteira, o conceito de integração, porém, assume diferentes nuances. Machado (2009) explica que enquanto a integração regional/ cooperação binacional são aquelas acordadas entre os governos centrais de cada país, a integração transfronteiriça se dá em nível local, de modo formal, institucionalizado e/ou informal. Na integração transfronteiriça, pesa, portanto, o cotidiano de relações entre os habitantes das cidades de fronteira e destes com aqueles que se deslocam por ela com frequência.

Nas cidades geminadas da fronteira platina, o modo como estão articuladas tem impacto sobre as relações locais, ao dificultarem ou facilitarem a travessia para o outro lado, tanto de produtos quanto de pessoas (incluindo os jornais e suas línguas). No entanto, nesses pontos fronteiriços, nem sempre a presença de um conector, como a ponte, resulta em maior integração, como já mostrou Grimson (2000; 2002), em seus estudos sobre a ponte Encarnación/Posadas (Paraguai/Argentina). Em cidades de maior tráfego internacional, a presença de postos de controle e de fiscalização também pode inibir a integração transfronteiriça. E isso afeta, inclusive, os contatos linguísticos, segundo o relato de um professor do programa Escolas Bilíngues de Fronteira, trazido por Bein (2012, p. 110):

donde hay puentes para el transporte terrestre sobre el río Uruguay, con puestos policiales y aduana a ambos lados de la frontera, la población es

\footnotetext{
${ }^{2}$ Conforme do Mapa elaborado pelo Grupo Retis/UFRJ (online). Disponível em:www.retis.igeo.ufrj.br/. Acesso em: março de 2014
} 
monolingüe o bilingüe castellano-portugués sin mezclar las lenguas; en cambio, donde hay "frontera seca" o se cruza el río mediante botes o balsas desde hace muchas generaciones -en actividades entre las que no se puede descartar el contrabando a pequeña escala- se forma el portuñol.

$\mathrm{Na}$ integração transfronteiriça, os jornais atuam de um modo muito relevante, reforçando sentidos de convergência ou divergência constituídos nesse espaço. Diversos estudos têm se dedicado à discursivização efetuada por jornais fronteiriços, em suas notícias, sobre a cidade internacional vizinha, sobre a integração regional, sobre a ideia de fronteira, entre outros temas, dos quais podemos citar os de Grimson (2002), Muller (2003) e Raimondi e Weber (2011). Contudo, entendemos que, para além do "discurso sobre" presente no noticiário (MARIANI, 1996), um dos modos pelos quais os jornais produzem sentidos e atuam sobre a integração fronteiriça se dá por meio de sua circulação para aquém ou além da linha divisória, contribuindo, assim, para um sentimento de comunidade, que seria reforçado pelo compartilhamento das mesmas notícias, das mesmas histórias de ficção, da mesma língua, à semelhança do que já postulava Anderson (2008), para a formação das nações europeias.

Em termos de práticas linguísticas, a fronteira platina constitui um continuum que vai do Rio da Prata até terras paraguaias, apresentando diversificadas situações de contato e intercâmbio entre as línguas espanhola, portuguesa e guarani, bem como entre as diversas línguas de imigração que compõem a matriz étnica local (STURZA, 2005). Em geral, o lado brasileiro da fronteira apresenta uma predominância do português como língua materna, ainda que com influência do espanhol no léxico e na fonéticafonologia, observando-se situações de contato linguístico mais intensas nos lados uruguaio, argentino e paraguaio. Já no que tange ao reconhecimento das línguas pelos Estados Nacionais, o português é língua oficial e nacional do Brasil; a língua espanhola é nacional e oficial na Argentina, Paraguai e Uruguai; e a língua guarani é co-oficial no Paraguai.

As cidades-gêmeas são também aquelas que figuram entre os pontos de mais intenso contato entre as línguas portuguesa, espanhola e guarani, na região platina. Nelas, essas línguas, especialmente o português e o espanhol, estariam mais propensas a funcionar como línguas de interface, isto é, como pertencentes a um conjunto de representações histórico-sociais e interculturais que as identificam como tais e que, por isso, se organizam politicamente para significarem a fronteira nos seus variados aspectos (STURZA; FERNANDES, 2009). 
No contexto fronteiriço platino, portanto, os jornais locais poderiam circular em um ou mais países e utilizar uma ou mais dessas línguas para compor suas notícias. Tais possibilidades nos levaram a questionar se a circulação transfronteiriça de jornais acontece ou não e quais línguas são usadas em uma e outra situação. Também, a nos perguntar como esses usos jornalísticos inscrevem sentidos políticos para as línguas na enunciação fronteiriça. E, por fim, qual a relação entre integração, circulação de jornais e uso de línguas por esses veículos, nas cidades gêmeas da fronteira.

Para desenvolver o estudo, inicialmente, selecionamos as 20 cidades-gêmeas da fronteira platina assinaladas na Proposta de Reestruturação do Programa de Desenvolvimento da Faixa de Fronteira, desenvolvida pelo Programa de Desenvolvimento da Faixa de Fronteira do Ministério da Integração Nacional (BRASIL, 2005). O mapa a seguir (Figura 1) identifica essas cidades, as localiza geograficamente e indica seu modo de articulação.

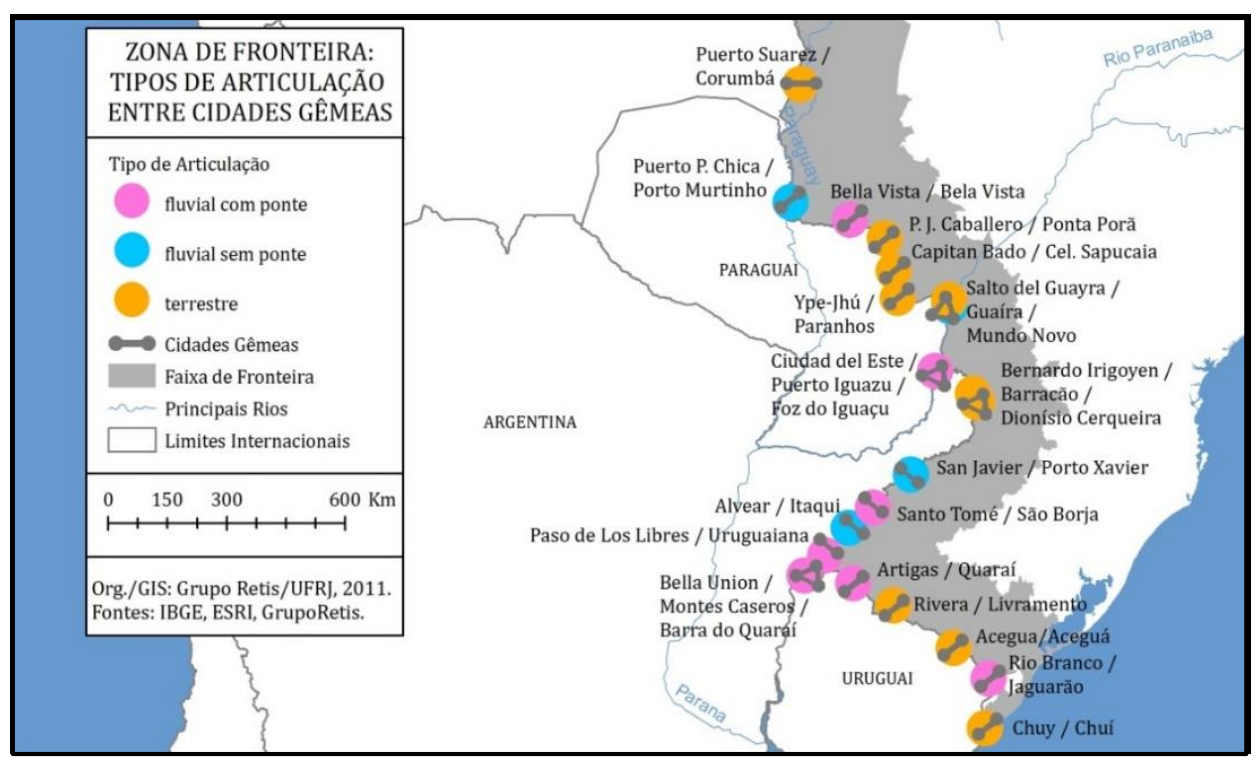

Figura 1- Limites entre as cidades-gêmeas da fronteira de Brasil com Uruguai, Argentina e Paraguai. Fonte: Grupo Retis/UFRJ (online).

Em seguida, identificamos aquelas que possuíam pelo menos um jornal editado localmente, no lado brasileiro, e selecionamos o de maior circulação. A coleta dos jornais se deu de sul a norte do Brasil e ocorreu entre os anos de 2010 e 2014. O próximo passo foi averiguar as cidades em que esses periódicos circulavam, conforme indicação explícita presente no expediente ou na capa do exemplar. Com isso, pudemos verificar em que pontos da fronteira do Brasil com Argentina, Uruguai e Paraguai havia jornais brasileiros com projeção sobre o país vizinho e em que pontos isso não acontecia. Por fim, lançamos nosso olhar sobre as línguas usadas por esses jornais para a publicação de suas notícias. 
Buscamos interpretar esses dados a partir de trabalhos sobre mídia e jornalismo locais, entre os quais se incluem os de Dornelles (2005) e Peruzzo (2003), bem como de estudos relacionados à Política de Línguas, entre eles, os de Guimarães (2003, 2005), Orlandi (2002), Mariani (2008), Sturza (2005, 2006) e Zoppi-Fontana (2009). Acreditamos que o estudo possa contribuir para o conhecimento sobre a política de línguas na fronteira, o jornalismo fronteiriço e as possibilidades de integração que eles conformam. A fronteira, afinal, não está somente nos limites naturais, nos marcos e nas aduanas, se constrói também nas vivências cotidianas, no nível do simbólico, como o da circulação dos jornais e das línguas nesse espaço limítrofe. E esse limite simbólico, é importante mencionar, é uma fronteira mais difícil de cruzar do que aquela dos limites físicos.

Assim, este artigo está dividido em dois tópicos. O primeiro busca entender os jornais fronteiriços como jornais locais e avaliar seu papel na criação de um sentimento comunitário transfronteiriço, bem como apresenta os resultados sobre a circulação de jornais nas cidades geminadas da fronteira de Brasil (BR) com Uruguai (UY), Argentina (AR) e Paraguai (PY), relacionando-a à integração local. O segundo tópico interpreta a questão das línguas dos jornais a partir do conceito de Política de Línguas, em contraposição ao de Política Linguística, entendendo a fronteira como um espaço de enunciação e de distribuição política para cada uma delas. Apresenta dados sobre as línguas usadas pelos jornais fronteiriços e estabelece relações com sua área de abrangência, interpretando-os a partir dessa perspectiva. Por fim, as considerações finais apontam para as mudanças desse panorama e para a necessidade de estudos diacrônicos sobre jornais e línguas de fronteira.

\section{A circulação de jornais nas cidades-gêmeas da fronteira.}

Entendemos que a integração transfronteiriça, aquela assentada no local (MACHADO, 2009), ocorre, dentre diversos outros modos, por meio da intervenção no espaço público feita pela imprensa de fronteira. E essa intervenção se dá não apenas pela difusão noticiosa de um discurso positivo ou negativo sobre o "outro lado", sobre o nacional ou sobre a integração regional. Por suas particularidades, a imprensa fronteiriça atua na integração das comunidades locais ao delimitar essa comunidade no próprio ato de delimitar sua audiência. Nos termos de Anderson (2008), a imprensa fronteiriça ajudaria a criar uma comunidade imaginada local, ao incluir ou excluir o país adjacente do alcance de suas notícias. Em nosso entendimento, os jornais são, ao 
mesmo tempo, produtores e reprodutores desse sentimento, de modo que, o compartilhamento das mesmas informações produziria um imaginário de pertencimento a um lugar, que pode ser o lugar do nacional ou o lugar do transfronteiriço.

Pode-se dizer que a imprensa da fronteira contribui para a integração transfronteiriça ao ajudar a criar, no imaginário social, uma ideia de "local". Segundo Peruzzo (2003), o local se constitui num espaço característico constituído por partes que se relacionam, mas que ora se identificam, dependem umas das outras, e ora são excludentes. No entanto, o local, ao mesmo tempo em que não permite a demarcação exata de limites, também carrega o sentido de um espaço determinado, de um lugar específico, no qual o sujeito se sente inserido e partilha sentidos com seus semelhantes. Quanto aos jornais locais, segundo Dornelles (2005), eles se caracterizam por ter uma área de abrangência mais restrita, localizada, e manter vínculos muito próximos com sua comunidade de leitores. Assim, a imprensa de fronteira, apesar do público internacional que pode possuir, funciona como uma imprensa local.

O local na fronteira pode incluir apenas as cidades brasileiras próximas ou pode envolver, também, as cidades internacionais adjacentes. Jornais publicados na cidade brasileira de Uruguaiana, no início do século XX, por exemplo, abrangiam uma área cujos municípios estavam distantes cerca de 500 quilômetros um do outro, circulando de São Borja a Jaguarão, também cidades brasileiras. O jornal uruguaianense A Voz do Povo, por sua vez, em 1905 trazia como slogan "A Voz do Povo é a folha de maior circulação na Fronteira do Alto Uruguai”. Ou seja, o local se delimitava pela própria condição de ser fronteira brasileira, o que significa que essas cidades geograficamente distantes convergiam em uma unidade social, política, econômica e cultural.

Hoje, o local dos jornais fronteiriços é geograficamente mais restrito, em razão do maior número de municípios e habitantes, bem como da maior quantidade de jornais em funcionamento. Desse modo, podemos encontrar, em quase todas as cidades limítrofes platinas, pelo menos um jornal nelas editado, isto é, cuja empresa jornalística está sediada na cidade, com funcionários que ali residem e contando com assinaturas e anúncios da comunidade local. Esses jornais costumam circular no lugar em que estão sediados e nos municípios do seu entorno imediato. A pesquisa identificou que apenas três (Chuí, Paranhos e Coronel Sapucaia) das 20 cidades investigadas não possuíam produção local de um jornal impresso no momento da coleta dos dados (Ver Quadro 1). 
A questão interessante no jornalismo de fronteira é que, em termos geográficos, muitas vezes, a cidade mais próxima é, justamente, a cidade-gêmea internacional, de modo que, se o critério para definição do local fosse apenas geográfico, ela seria a primeira a figurar como audiência do jornal fronteiriço. Veja-se o caso atual da cidade de Uruguaiana, que se distancia apenas cerca de $8 \mathrm{~km}$ do núcleo urbano de Paso de los Libres, na Argentina, com a qual é geminada e unida por uma ponte internacional. A cidade-gêmea está geograficamente muito mais próxima que as cidades brasileiras vizinhas, como Alegrete (145 km), Barra do Quaraí (72km), Garruchos (300 km), Itaqui (104 km), Maçambará (147 km), Quaraí (123 km) e São Borja $(180 \mathrm{~km})^{3}$. Contudo, o jornal uruguaianense Diário da Fronteira circula em todas essas cidades brasileiras e não na cidade-gêmea internacional, como podemos ver pela imagem de capa do jornal, a seguir (Figura 2):

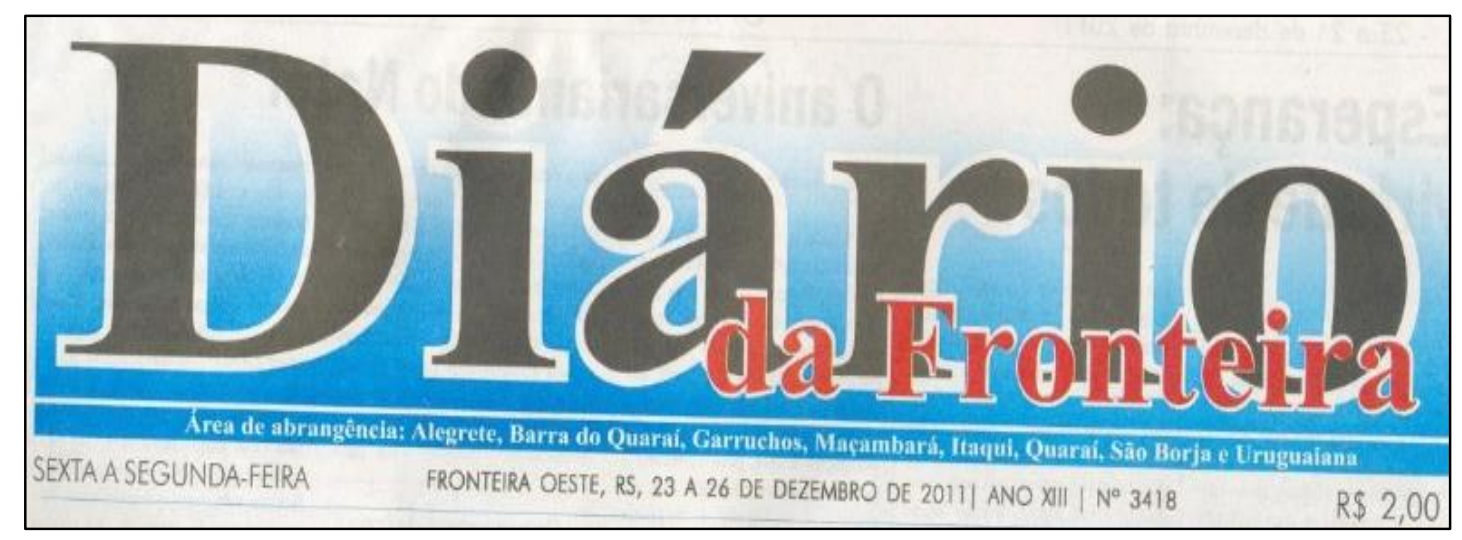

Figura 2- Abrangência do jornal Diário da Fronteira, de Uruguaiana. Fonte: arquivo pessoal da autora.

Diferente é a situação do jornal Folha Barrense, produzido na cidade de Barra do Quaraí, na tríplice fronteira Brasil-Argentina-Uruguai. De acordo com a indicação de abrangência do jornal expressa em sua capa, exposta na Figura 3, o periódico alcança a cidade geminada de Bella Unión (UY), com a qual se conecta por duas pontes (uma ferroviária e outra rodoviária) e de cujo núcleo urbano se distancia por $6 \mathrm{~km}$. Também chega à outra cidade gêmea, Monte Caseros (AR), cujo núcleo urbano está a cerca de 7 km de distância de Barra de Quaraí e com o qual esta se conecta por balsas a partir do porto de Bella Unión ${ }^{4}$. A terceira cidade internacional que o jornal alcança é a argentina

\footnotetext{
${ }^{3}$ Distâncias aproximadas obtidas por meio do Google Maps, considerando rotas terrestres para circulação de automóveis.

${ }^{4}$ Distâncias e modos de acesso obtidos por meio do Observatorio de Fronteras do Centro de Formación para la Integración Regional (CEFIR), no artigo intitulado "Alternativas de solução de problemas
} 
Passo de los Libres, que se localiza a, aproximadamente, $80 \mathrm{~km}$ de Barra do Quaraí. Entre as cidades brasileiras, o Folha Barrense chega também a três: à própria Barra do Quaraí, a Uruguaiana $(70 \mathrm{~km})$ e a Caxias do Sul $(750 \mathrm{~km})$, esta não fronteiriça, localizada no noroeste do estado do Rio Grande do Sul ${ }^{5}$.

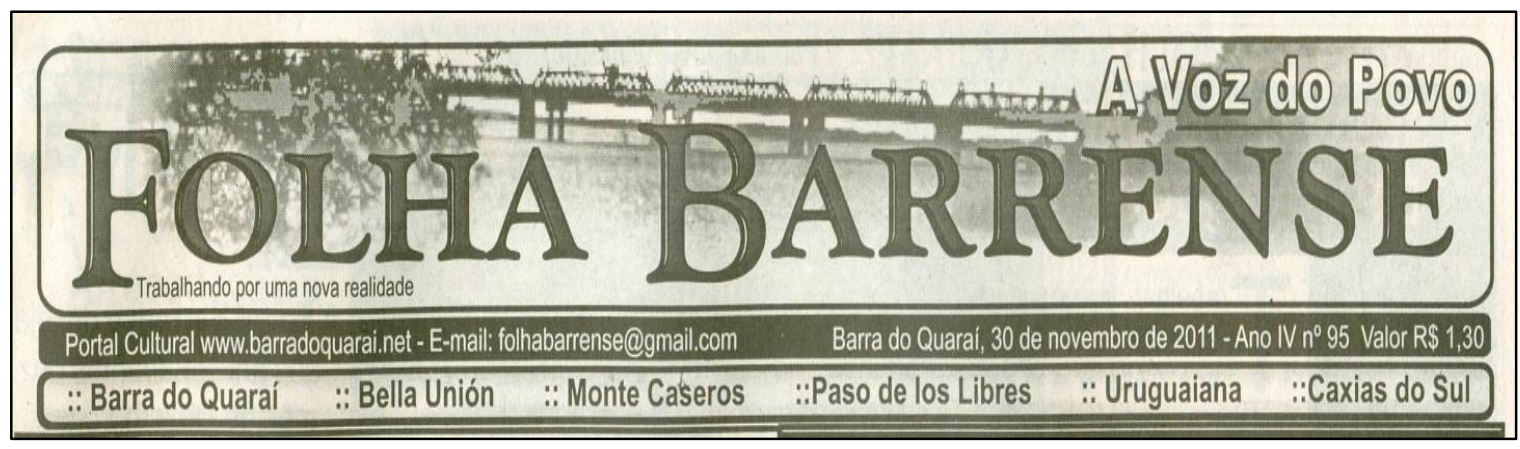

Figura 3- Abrangência do jornal Folha Barrense, de Barra do Quaraí. Fonte: arquivo pessoal da autora.

Desse modo, percebemos que as distâncias são mais que físicas; estão estabelecidas nas relações entre os lugares. Existem, portanto, fronteiras simbólicas constituídas nesses lugares, as quais, de algum modo, são também constituídas pela circulação dos jornais. Na sequência, apresentamos o Quadro 1, que identifica as cidades-gêmeas da fronteira Brasil-Uruguai-Argentina-Paraguai; a presença de jornais produzidos na cidade fronteiriça brasileira; o jornal escolhido para estudo; a data do exemplar mobilizado para análise e as cidades de circulação desse jornal.

fronteiriços de saúde através de contratos de prestação de serviços celebrados entre o Município de Barra do Quaraí e pessoas jurídicas sediadas em Bella Unión”, de autoria de Hamilton Santos Rodrigues Avelar Fortunato. Disponível em: http://cefir.org.uy/fronteras/images/Santos_Rodriguez_y_Avelar_Fortunato._Alternativas_de_solu.pdf. Acesso em: 12 jul. 2015.

${ }^{5}$ Idem nota 2. 


\begin{tabular}{|c|c|c|c|c|}
\hline $\begin{array}{l}\text { Cidade } \\
\text { brasileira }\end{array}$ & Cidade-gêmea & Jornal local & Edição & Circulação \\
\hline Chuí & Chuy (UY) & -- & -- & -- \\
\hline Jaguarão & Río Branco (UY) & $\begin{array}{l}\text { A Folha } \\
\text { Regional }\end{array}$ & $02 / 06 / 10$ & Jaguarão, Arroio Grande e Herval \\
\hline Aceguá & Acegua (UY) & $\begin{array}{l}\text { Manchete } \\
\text { Regional }\end{array}$ & $26 / 11 / 10$ & Aceguá, Acegua \\
\hline $\begin{array}{l}\text { Santana do } \\
\text { Livramento }\end{array}$ & Rivera(UY) & A Plateia & $17 / 09 / 10$ & Santana do Livramento, Rivera \\
\hline Quaraí & Artigas (UY) & $\begin{array}{l}\text { Folha de } \\
\text { Quaraí }\end{array}$ & $15 / 04 / 10$ & Quaraí, Artigas \\
\hline $\begin{array}{l}\text { Barra do } \\
\text { Quaraí }\end{array}$ & $\begin{array}{l}\text { Bella Unión (UY) } \\
\text { Monte Caseros (AR) }\end{array}$ & $\begin{array}{l}\text { Folha } \\
\text { Barrense }\end{array}$ & $30 / 11 / 11$ & $\begin{array}{l}\text { Barra do Quaraí, Bella Unión, Monte Caseros, } \\
\text { Paso de los Libres, Uruguaiana, Caxias do Sul }\end{array}$ \\
\hline Uruguaiana & $\begin{array}{l}\text { Paso de los Libres } \\
\text { (AR) }\end{array}$ & $\begin{array}{l}\text { Diário da } \\
\text { Fronteira }\end{array}$ & $25 / 03 / 10$ & $\begin{array}{l}\text { Alegrete, Barra do Quaraí, Garruchos, Itaqui, } \\
\text { Maçambará, Quaraí, São Borja, Uruguaiana }\end{array}$ \\
\hline Itaqui & Alvear (AR) & $\begin{array}{l}\text { Folha de } \\
\text { Itaqui }\end{array}$ & $13 / 06 / 10$ & Itaqui, Maçambará \\
\hline São Borja & Santo Tomé (AR) & $\begin{array}{l}\text { Folha de São } \\
\text { Borja }\end{array}$ & $01-15 / 02 / 11$ & São Borja, Santo Antônio das Missões \\
\hline Porto Xavier & San Javier (AR) & $\begin{array}{l}\text { A Gazeta do } \\
\text { Povo }\end{array}$ & $30 / 09 / 10$ & $\begin{array}{l}\text { Cândido Godói, Campina das Missões, Porto } \\
\text { Xavier, Porto Lucena }\end{array}$ \\
\hline Barracão & $\begin{array}{l}\text { Bernardo de Irigoyen } \\
\text { (AR) }\end{array}$ & $\begin{array}{l}\text { Jornal da } \\
\text { Fronteira }\end{array}$ & $17 / 04 / 14$ & $\begin{array}{l}\text { Barracão, Bom Jesus do Sul, Bela Vista da } \\
\text { Caroba, Flor da Serra do Sul, Manfrinópolis, } \\
\text { Pérola do Oeste, Pranchita, Salgado Filho, Santo } \\
\text { Antônio do Sudoeste, Anchieta, Campo Erê, } \\
\text { Dionísio Cerqueira, Guaraciaba, Guarujá do Sul, } \\
\text { Palma Sola, São José do Cedro, Bernardo de } \\
\text { Irigoyen, San Antonio }\end{array}$ \\
\hline $\begin{array}{l}\text { Dionísio } \\
\text { Cerqueira }\end{array}$ & $\begin{array}{l}\text { Bernardo de Irigoyen } \\
\text { (AR) }\end{array}$ & $\begin{array}{l}\text { Tribuna } \\
\text { Regional }\end{array}$ & $12 / 04 / 14$ & Oeste de SC e Sudoeste do Paraná \\
\hline $\begin{array}{l}\text { Foz do } \\
\text { Iguaçu }\end{array}$ & $\begin{array}{l}\text { Puerto Iguazú (AR) } \\
\text { Ciudad Del Este } \\
\text { (PY) }\end{array}$ & $\begin{array}{l}\text { A Gazeta do } \\
\text { Iguaçu }\end{array}$ & $12-13 / 04 / 14$ & Não consta \\
\hline Guaíra & $\begin{array}{l}\text { Saltos del Guairá } \\
(\mathrm{PY})\end{array}$ & $\begin{array}{l}\text { Jornal Rio } \\
\text { Paranazão }\end{array}$ & $24-31 / 10 / 14$ & Não consta \\
\hline $\begin{array}{l}\text { Mundo } \\
\text { Novo }\end{array}$ & $\begin{array}{l}\text { Saltos del Guairá } \\
\text { (PY) }\end{array}$ & O Liberal & $23-27 / 10 / 14$ & Não consta \\
\hline Paranhos & Ype Jhu (PY) & -- & -- & -- \\
\hline $\begin{array}{l}\text { Coronel } \\
\text { Sapucaia }\end{array}$ & Capitán Bado (PY) & -- & -- & 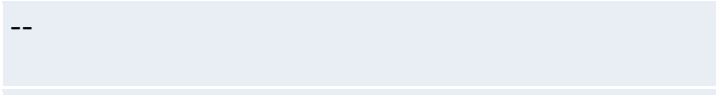 \\
\hline Ponta Porã & $\begin{array}{l}\text { Pedro Juan Caballero } \\
\text { (PY) }\end{array}$ & $\begin{array}{l}\text { Jornal } \\
\text { Regional }\end{array}$ & $12-13 / 04 / 14$ & $\begin{array}{l}\text { Antônio João, Bela Vista, Aral Moreira, } \\
\text { Amambai, Laguna Carapã, Dourados, Campo } \\
\text { Grande, Caracol, Maracaju, Jardim e Porto } \\
\text { Murtinho. }\end{array}$ \\
\hline Bela Vista & $\begin{array}{l}\text { Bella Vista } \\
\text { (PY) }\end{array}$ & $\begin{array}{l}\text { Tribuna da } \\
\text { Fronteira }\end{array}$ & $24-30 / 03 / 14$ & $\begin{array}{l}\text { Bela Vista, Jardim, Porto Murtinho, Caracol, } \\
\text { Bonito, Antonio João, Guia Lopes da Laguna, } \\
\text { Ponta Porã, Campo Grande. }\end{array}$ \\
\hline $\begin{array}{l}\text { Porto } \\
\text { Murtinho }\end{array}$ & $\begin{array}{l}\text { Puerto Palma Chica } \\
\text { (PY) }\end{array}$ & $\begin{array}{l}\text { Tribuna } \\
\text { Murtinhense }\end{array}$ & $01 / 05 / 14$ & Não consta \\
\hline
\end{tabular}

\footnotetext{
Quadro 1- Circulação dos jornais fronteiriços de cidades-gêmeas platinas.
} 
No quadro anterior, as cidades internacionais que fazem parte da área de abrangência de jornais brasileiros estão marcadas em negrito. Dos 17 jornais estudados, cinco circulam para além da divisória internacional, seja na cidade-gêmea correspondente ou em outras próximas a ela. Assim, os jornais Manchete Regional de Aceguá, A Plateia de Santana do Livramento e Folha de Quarai de Quaraí, todos na fronteira com o Uruguai, circulam apenas na sua cidade gêmea internacional, que é, respectivamente, Acegua, Rivera e Artigas. Já o Folha Barrense de Barra do Quaraí, circula nas duas cidades-gêmeas com que esta faz divisa, Monte Caseros (AR) e Bella Unión (UY), mas também na vizinha Paso de los Libres (AR) com quem não é geminada. O mesmo ocorre com o Jornal da Fronteira de Barracão (BR), que circula na cidade geminada de Bernardo de Irigoyen (AR), mas também na vizinha e não gêmea San Antonio (AR).

Desconsiderando os jornais de Foz do Iguaçu, Porto Murtinho, Guaíra e Mundo Novo, que não explicitam sua área de circulação, podemos afirmar que a maioria dos jornais fronteiriços platinos não inclui a cidade-gêmea ou outra do país vizinho em sua cobertura, restringindo o local ao lado brasileiro da fronteira e criando, portanto, um sentimento de comunidade que é ligado ao nacional e não ao transfronteiriço. Esse é um dado interessante, uma vez que, em todos os pontos da fronteira platina, encontramos uma situação de predomínio e projeção da identidade cultural brasileira, segundo consta na Proposta de Reestruturação do Programa de Desenvolvimento da Faixa de Fronteira (BRASIL, 2005). Isso significa que, potencialmente, os jornais do Brasil teriam condições favoráveis para se tornarem transfronteiriço, já que encontrariam do outro lado uma área já acostumada com produtos culturais brasileiros, um público que já teve contatos anteriores com a cultura brasileira e com língua portuguesa.

Sobre os jornais que circulam do outro lado da linha divisória, identificamos que eles se localizam na fronteira com o Uruguai e com a Argentina, não havendo nenhum com esse perfil nos limites com o Paraguai. Mais do que isso, vemos que essa prática é mais frequente entre os jornais brasileiros da divisa com o Uruguai.

Além disso, dessas cinco cidades-gêmeas em que há jornais transfronteiriços, três se organizam como fronteiras terrestres, Aceguá /Acegua (BR/UY), Santana do Livramento/ Rivera (BR/UY) e Barracão/Bernardo Irigoyen (BR/AR) e duas como fronteiras fluviais com ponte, Quaraí/Artigas (BR/UY) e a tríplice fronteira Bela União/Monte Caseros/Bella Unión (BR/AR/UY). Nenhuma localidade ligada por balsas tem jornais circulando para além da linha divisória. Também é interessante observar que 
os jornais transfronteiriços não estão presentes naquelas cidades-gêmeas de maior porte, responsáveis por grande parte do transporte de bens e pelo turismo internacionais da região, como é o caso de Uruguaiana/Paso de los Libres (BR/AR) e São Borja/Santo Tomé (BR/AR), o que corrobora os estudos de Grimson (2000, 2002) e Bein (2013), no sentido de que a ponte, o controle aduaneiro e imigratório, o intenso tráfego e as dificuldades e significados deles decorrentes podem inibir a integração local.

Assim, a ideia da fronteira como local que envolve dois países está constituída na circulação de cinco jornais, a maioria deles em cidades geminadas que não se caracterizam como corredor de passagem para produtos e pessoas no Mercosul e situadas nas fronteiras mais meridionais do Brasil. A integração transfronteiriça, portanto, se estabelece nessas cidades-gêmeas por meio do funcionamento de sua imprensa, que, ao circular nos dois lados da fronteira, cria uma comunidade de leitores e um sentimento de pertencimento a um local, que é transfronteiriço. Por outro lado, se a circulação de jornais dos dois lados da linha divisória funciona como elemento de integração transfronteiriça por si só, por outro, seria necessário conhecer que conteúdos esses jornais brasileiros fazem circular do outro lado, a fim de identificar se a cobertura jornalística também compreende os países limítrofes, se a expressão linguística incorpora a língua nacional vizinha, enfim, se os sentidos projetados são, de fato, integradores.

No próximo tópico, buscamos responder a um desses questionamentos: quais são as línguas usadas por esses jornais ao delimitarem apenas a um ou a ambos os lados da fronteira como sua área de abrangência. Mais do que identificar a língua de enunciação, porém, procuramos interpretar os sentidos que esses usos projetam ao associarem a língua a um determinado espaço local, que pode ser nacional ou transfronteiriço. Assim, acreditamos que o uso das línguas produz um discurso sobre o local na fronteira e sobre a integração que nele ocorre.

\section{Os sentidos políticos das línguas inscritos na circulação dos jornais fronteiriços.}

Considerando que a abrangência de jornais locais contribuiu para a constituição e difusão de um sentimento de pertencimento a um espaço geográfico, social e cultural, as línguas que o jornal usa em sua enunciação são sinalizadoras das línguas que circulam nesse espaço e dos sentidos nelas inscritos. Desse modo, quanto mais integradas as cidades geminadas, maior seria esse fluxo linguístico através das fronteiras; mais naturalizadas seriam para os habitantes locais as línguas faladas nos 
dois lados da linha divisória e, como destacam Sturza e Fernandes (2009), mais elas funcionariam como línguas de interface.

Mais do que isso, contudo, as línguas mobilizadas pelos jornais em suas publicações são sinalizadoras de um imaginário sobre as línguas e sobre a fronteira que está presente nesse espaço e que os jornais, ao circularem, ajudam a produzir e a reproduzir, simultaneamente. Essa área de circulação dos jornais é, nesse sentido, um espaço de enunciação. Guimarães (2005) os descreve como espaços de funcionamento de línguas, nos quais elas se dividem, redividem, se misturam, desfazem e transformam por uma disputa incessante. Segundo ele, é nos espaços de enunciação que os falantes se constituem como sujeitos divididos por seus direitos ao dizer e aos modos de dizer. Resumidamente, a partir da perspectiva desse autor, sujeitos falantes distribuem as línguas em categorias, gerando subdivisões políticas, que organizam a própria política de línguas em voga em um determinado espaço enunciativo. A política de línguas é, desse modo, aquela constituída por processos institucionais menos evidentes, presentes de forma implícita nos usos diferenciados (e que produzem diferenças) das línguas (ORLANDI, 2002). Sendo assim, jornais de fronteira ao relacionarem línguas a áreas de circulação evidenciam uma política de línguas para as cidades fronteiriças.

Encontramos um exemplo do funcionamento da noção de distribuição política das línguas na obra de Guimarães: tomando como objeto o espaço de enunciação brasileiro, Guimarães (2003) conclui que nele funcionam o português (língua oficial, nacional e língua materna da grande maioria da população), línguas indígenas, línguas de imigração, línguas de fronteira e, mesmo que precariamente, línguas africanas. No entanto, na distribuição imaginária delas para os falantes brasileiros ocorrem algumas sobreposições, das quais a principal é a da língua oficial com a língua nacional, e destas com a língua materna (GUIMARÃES, 2003). Assim, os jornais fronteiriços, ao usarem as línguas espanhola, guarani ou portuguesa para enunciar, fazem uma distribuição política dessas línguas como nacionais ou locais da fronteira, entre outras possibilidades.

Sturza (2006) sugere que a zona de fronteira do Prata constitui um espaço de enunciação particular em relação aos países que compõem a região, por ela denominado de "espaço de enunciação fronteiriço". A autora pensa esse espaço com base na realidade da fronteira platina, mais especificamente, da fronteira Brasil-Uruguai, e o apresenta como constituído pelas línguas nacionais de cada país, o português e o espanhol e, ainda, pelas práticas linguísticas decorrentes do contato dessas línguas. 
Assim, propõe Sturza (2006), o sujeito enunciador fronteiriço funciona como figura política que se move entre duas línguas, afetado pelo imaginário da fronteira como limite entre dois mundos, onde começam, mas também terminam os domínios de uma e outra prática linguística (STURZA, 2006).

Dessa forma, no espaço de enunciação fronteiriço é possível o transbordamento das línguas para além das fronteiras nacionais. Mas, diferentemente do que ocorre em um espaço de enunciação transnacional, em que as línguas ultrapassam a fronteiras nacionais sem desvincularem-se simbolicamente do Estado-nação que representam (ZOPPI-FONTANA, 2009), na fronteira, o apagamento da relação Estado-língua é potencialmente possível, na prática cotidiana de contato entre as línguas que conformam o local. Nesse sentido, quanto mais integradas são as cidades fronteiriças, menos as suas línguas remeteriam ao Estado-nação ao qual se vinculam como nacionais ou oficiais; mais elas se significariam como línguas de fronteira no imaginário local.

Se voltarmos a observar a circulação dos jornais fronteiriços apresentada no tópico anterior, relembraremos que, dos 17 jornais estudados, oito circulam apenas no lado brasileiro e cinco para além da divisória internacional. A questão que se coloca, agora, é qual ou quais línguas esses jornais usam para enunciar. Afinal, as línguas mobilizadas pelo jornal são aquelas que os veículos projetam como sendo da comunidade local-fronteiriça por eles delimitada, recorrendo, nos termos de Orlandi (2008), a um mecanismo de antecipação de seu interlocutor. Esse mecanismo refletiria as línguas que estão politicamente aptas a circular nessa comunidade fronteiriça. $O$ quadro a seguir (Quadro 3) descreve esses usos, a partir da análise da presença das línguas nos exemplares selecionados para este estudo. 


\begin{tabular}{|l|l|l|}
\hline Jornal local & Circulação & Línguas usadas \\
\hline A Folha Regional & BR & Portuguesa \\
\hline Manchete Regional & BR, UY & Portuguesa e espanhola \\
\hline A Plateia & BR, UY & Portuguesa e espanhola \\
\hline Folha de Quaraí & BR,UY & Portuguesa e espanhola \\
\hline Folha Barrense & BR, UY, AR & Portuguesa e espanhola \\
\hline Diário da Fronteira & BR & Portuguesa \\
\hline Folha de Itaqui & BR & Portuguesa \\
\hline Folha de São Borja & BR & Portuguesa \\
\hline A Gazeta do Povo & BR & Portuguesa \\
\hline Jornal da Fronteira & BR, AR & Portuguesa e espanhola \\
\hline Tribuna Regional & BR & Portuguesa \\
\hline A Gazeta do Iguaçu & Não consta & Portuguesa \\
\hline Jornal Rio Paranazão & Não consta & Portuguesa \\
\hline O Liberal & Não consta & Portuguesa \\
\hline Jornal Regional & BR & Portuguesa e espanhola \\
\hline Tribuna da Fronteira & BR & Portuguesa \\
\hline Tribuna Murtinhense & Não consta & Portuguesa \\
\hline
\end{tabular}

Quadro 2- As línguas dos jornais fronteiriços

A interpretação do quadro mostra que dos 17 jornais estudados, 11 usam apenas a língua portuguesa em sua enunciação. Isso já nos permite concluir que há uma primazia no uso dessa língua entre os jornais brasileiros das cidades-gêmeas fronteiriças. Podemos refletir, em consonância com Mariani (2008, p. 26), que esse dado aponta para o fato de que funciona, no Brasil, um imaginário de unidade que coaduna língua portuguesa e Estado Nacional, o qual coloca língua nacional e nação (povo) em uma "relação especular e de unidade imaginária". Nesse caso, jornais do Brasil se associariam "naturalmente" à língua portuguesa, que é a língua nacional do país. Ainda, segundo a autora (2008), nação e língua nacional são imaginadas em uma homogeneidade política necessária que apaga a heterogeneidade historicamente constitutiva dos seus processos de constituição. Em se pensando nas cidades-gêmeas fronteiriças, isso significa que a heterogeneidade linguística característica da comunidade local (STURZA, 2005) é apagada em prol da língua nacional do país do qual cada cidade faz parte. 
Levando em conta, agora, apenas os jornais que indicam sua área de circulação, apreendemos que sete dos que usam somente a língua portuguesa circulam exclusivamente no lado brasileiro. São eles os jornais A Folha Regional, Diário da Fronteira, Folha de Itaqui, Folha de São Borja, A Gazeta do Povo, Tribuna Regional e Tribuna da Fronteira, a maioria editada em cidades da fronteira com a Argentina e o Paraguai. Isso reforça a ideia anterior de que existe uma sobreposição entre língua e nação: se o jornal é brasileiro e sua circulação se dá apenas no lado brasileiro da fronteira, a língua autorizada para esse espaço de enunciação é a portuguesa. Assim, se o jornal projeta uma comunidade local-fronteiriça que envolve cidades do Brasil e que exclui as do país vizinho, a língua portuguesa se inscreve como marca política dessa divisão.

A língua espanhola é mobilizada em conjunto com a portuguesa por seis desses 17 jornais fronteiriços. Em cinco casos, trata-se de jornais transfronteiriços, isto é, que incorporam na sua abrangência as cidades dos países limítrofes. São eles os jornais Manchete Regional, A Plateia, Folha de Quarai, Folha Barrense e Jornal da Fronteira, todos produzidos em cidades da fronteira do Brasil com o Uruguai e a Argentina. Assim, se visualizarmos o Quadro 2 como quem olha a fronteira platina de sul a norte, concluiremos que nas áreas mais ao sul, especialmente, na parte mais meridional dessa fronteira, o fluxo das línguas portuguesa e espanhola se dá de modo mais acentuado entre os dois lados da linha divisória, entre as cidades-gêmeas, por meio da enunciação dos jornais. O espaço de enunciação dessas comunidades transfronteiriças seria, portanto, um espaço mais plurilíngue que o das demais cidades-gêmeas no registro escrito, especialmente no jornalístico.

Nesses jornais transfronteiriços e bilíngues, o fato de circular "do outro lado" significa incorporar a língua do "outro país", nesse caso, a espanhola. Novamente, parece haver uma sobreposição entre língua e nação, mas, agora, relacionada à língua espanhola: cidades fronteiriças uruguaias, argentinas e paraguaias constituem espaços de enunciação da língua espanhola, ainda que limítrofes com o Brasil, geminadas, integradas e formando um local-transfronteiriço. Assim, se, por um lado, o incorporar as cidades geminadas vizinhas à área de circulação do jornal e incluir a língua espanhola à enunciação jornalística pode constituir um fator de integração local, por outro, tal integração parece não apagar a relação política da cidade com a nação em que se insere e da nação com sua língua nacional. 
Apenas um jornal de abrangência exclusivamente brasileira, o Jornal Regional, da cidade de Ponta Porã, usa a língua espanhola para enunciar. Essa situação nos faz pensar que o jornal projeta falantes de língua espanhola em território brasileiro. Nesse caso, a sobreposição identificada por Guimarães (2003) para a língua portuguesa, como nacional, oficial e materna do Brasil, seria contrariada pela enunciação do periódico. É, porém, uma situação peculiar dentro do quadro investigado.

Por fim, chama a atenção a ausência do guarani em todos os jornais analisados, mas, sobretudo, naqueles que circulam na fronteira com o Paraguai, onde a língua é mais difundida socialmente e desfruta de certo reconhecimento conferido pela oficialização, em 1992, e pelo ensino bilíngue, em funcionamento no país desde 1994 (ZAJÍKOVÁ, 2009). Como todos os jornais da fronteira paraguaia delimitam sua abrangência ao lado brasileiro, podemos interpretar que o guarani significa, nesse espaço, uma língua não brasileira, muito embora ela tenha raízes históricas nesse território e as fronteiras tenham sido, justamente, o lugar de refúgio da língua frente ao processo colonizador (MELIÁ, 1988).

Diferentemente do que ocorreu com a língua espanhola, que foi acolhida pelo jornal de Ponta Porã, apesar de este circular apenas no lado brasileiro, a língua guarani não foi incorporada por nenhum desses jornais. Entendemos que vários fatores podem colaborar para essa ausência do guarani, como a distribuição política da língua como nacional do Paraguai, bem como a sua associação à oralidade (resultando na ausência de leitores e escritores em guarani), às classes médias e baixas (RODRIGUEZZUCCOLILLO, 2000). No entanto, o que nos interessa assinalar aqui é que os jornais fronteiriços reforçam esses sentidos ao interditarem o guarani de sua enunciação.

Como ressalta Steinberger-Elias (2005), é corrente na sociedade a ideia de que tudo pode ser coberto jornalisticamente, de que tudo é dizível e representável pelo jornalismo, quando, na verdade, a atividade jornalística sempre resulta em uma seleção limitada de fatos noticiáveis. Poderíamos complementar que também resulta em uma seleção limitada de línguas. Desse modo, as línguas que não são mobilizadas pelo jornal deixam de existir no imaginário social, ou, no mínimo, se tornam menos relevantes. E, quando são mobilizadas, os lugares que aparecem, o modo como são organizadas, tornam-se a verdade sobre elas. A circulação dos jornais, portanto, não só produz um sentimento de comunidade na fronteira, que pode ser transfronteiriço ou não, como, produz, também, uma distribuição política das línguas nesse espaço local, por meio das línguas que usa em sua enunciação. 


\section{Considerações finais.}

O panorama sobre a circulação dos jornais fronteiriços, bem como sobre sua diversidade linguística, apresentado neste artigo não pretende ser, sob nenhum aspecto, definitivo. Como podemos perceber pela leitura do Quadro 1, os jornais cuja circulação foi estudada têm datas de publicação que variam de 2010 a 2014. Desde o início da coleta de dados até os dias de hoje, muitas mudanças podem ter acontecido na vida desses periódicos, desde a alteração da sua área de circulação (de modo que aqueles que antes eram transfronteiriços podem agora não ser e vice-versa) até o seu fechamento. Ambas as possibilidades são fortalecidas pelo fato de que, em sua maioria, trata-se de jornais jovens e de pequeno porte, enfrentando as dificuldades características do mercado em cidades pouco desenvolvidas economicamente. Dos jornais estudados, o mais antigo é de 1938; depois temos quatro fundados na década de 1970; um na década de 1980; quatro nos anos 1990 e, o maior número deles, sete, nos anos 2000.

Do mesmo modo, o panorama sobre a presença das línguas nesses jornais também pode ter sofrido modificações. Jornais monolíngues podem ter se convertido em bilíngues e vice-versa ou, quem sabe, ter incorporado línguas antes ausentes de suas páginas. Acompanhando a história de um desses jornais, o A Plateia, da cidade de Santana do Livramento (BR), limítrofe com Rivera (UY), percebemos que o jornal, em seus 77 anos de existência, já modificou algumas vezes o uso de línguas em sua publicação, tanto em termos de quais línguas adotava junto com o português (árabe, espanhol) quanto em termos de modo de apresentação dessas línguas (totalmente monolíngue, o mesmo texto em duas línguas, diferentes línguas para diferentes textos etc.).

Também, hoje, ações educacionais apoiadas pelo Mercosul têm buscado fomentar relações positivas entre as áreas de fronteira do bloco, em outras palavras, procurado promover a integração transfronteiriça. Muitas dessas ações têm como local de atuação, justamente, as cidades-gêmeas da fronteira. São exemplos as Escolas Interculturais Bilíngues de Fronteira, que abrangem várias cidades geminadas da região platina; as Escolas Técnicas Binacionais, situadas em Santana do Livramento (BR) e Rivera (UY), e a Universidade Federal da Integração Latino-Americana (UNILA), sediada em Foz do Iguaçu (BR). Essas práticas de aproximação entre os estudantes e docentes das cidades-gêmeas (nos dois primeiros casos) e da América Latina (no segundo caso) estão modificando as relações fronteiriças e, possivelmente, em um futuro próximo, afetarão seus modos e grau de integração. Sendo assim, o 
funcionamento da imprensa fronteiriça, tanto no aspecto da circulação quanto no das práticas linguísticas, também deverá passar por modificações.

Nesse sentido, um estudo diacrônico sobre os jornais de fronteira e suas práticas linguísticas seria elucidativo das transformações que as relações transfronteiriças têm vivenciado, ao longo dos anos. Poderíamos, com ele, identificar se a circulação dos jornais no país vizinho aumenta nos períodos históricos em que predominam políticas integradoras, como a do Mercosul atual, ou se permanece estável, independentemente dos acordos binacionais e regionais. Também, se as línguas mobilizadas por esses jornais variam, conforme o período histórico, bem como quais significados políticos assumem em cada um deles. Estudar a trajetória das línguas nos jornais de fronteira aportaria um capítulo interessante à História das Ideias Linguísticas.

\section{Referências bibliográficas.}

ANDERSON, B. Comunidades imaginadas: reflexões sobre a origem e a difusão do nacionalismo. São Paulo: Companhia das Letras, 2008.

BEIN, R. La política lingüística respecto de las lenguas extranjeras en la Argentina a partir de 1993. Tese (Doutorado área Romanistik - Spanisch). Universidade de Viena, 2012.

BRASIL. Ministério da Integração Nacional. Secretaria de Programas

Regionais. Programa de Desenvolvimento da Faixa de Fronteira. Proposta de Reestruturação do Programa de Desenvolvimento da Faixa de Fronteira. Brasília: Ministério da Integração Nacional, 2005.

DORNELLES, B. Características de jornais e leitores interioranos no final do século 20. Biblioteca On Line de Ciências da Comunicação, Covilhã/Portugal, v. 1, p. 1-15, 2005. Disponível em: www.bocc.ubi.pt/pag/dornelles-beatriz-jornais-interioranos.pdf. Acesso em: 30 abril 2011.

GRIMSON, A. El puente que separó dos orillas. Notas para uma crítica del esencialismo de la hermandad. In: GRIMSON, A. (org). Fronteras, naciones e identidades: la periferia como centro. Buenos Aires:Ciccus-La Crujía, 2000. P.201-231.

GRIMSON, A. El otro lado del río. Periodistas, nación y Mercosur en la Frontera. Buenos Aires, Eudeba, 2002.

GUIMARÃES, E. Enunciação e política de línguas no Brasil. Revista Letras, n.27, p. 47-53, 2003. Disponível em: http://w3.ufsm.br/revistaletras/letras27.html. Acesso em: 12 mai. 2011.

GUIMARÃES, E. Semântica do acontecimento. Campinas: Pontes, 2005.

MACHADO, L. Integração na faixa de fronteira. Revista Espaço Regional. Ano IV, $\mathrm{n}^{\mathbf{o}}$ 04, p. 6-8, dez. 2009.

MARIANI, B. O comunismo imaginário: práticas discursivas da imprensa sobre o PCB (1922 -1989). 1996. 256f. Tese (Curso de Linguística do Instituto de Estudos da 
Linguagem). Universidade Estadual de Campinas, 1996. Disponível em: http://www.bibliotecadigital.unicamp.br/document/?code=vtls000115692. Acesso em: 23 abr. 2013.

MARIANI, B. Língua nacional e pontos de subjetivação. Estudos Linguísticos, n. 37 (3), p. 25-31, set/dez, 2008. Disponível em http://www.gel.org.br/estudoslinguisticos/ volumes/37/EL_V37N3 03.pdf. Acesso em: 12 fev. 2011.

ORLANDI, E. Língua e conhecimento lingüístico: para uma história das idéias no Brasil. São Paulo: Cortez, 2002.

ORLANDI, E. Análise de Discurso: princípios e procedimentos. 8 ed. Campinas, SP: Contexto, 2008.

MELIÀ, B. Una nación, dos culturas. RP ediciones/Cepag: Asunción, 1988.

MÜLlER, K. Mídia e Fronteira. Publicação on line, 2003. Disponível em: http://www.midiaefronteira.com.br/index.htm . Acesso em: 01 jun 2011.

PERUZZO, C.M.K. Mídia local, uma mídia de proximidade. Revista Comunicação: veredas. Ano 2, $\mathrm{n}^{\mathrm{o}} 02$, novembro 2003. p. 65-89. Disponível em http://revcom.portcom.intercom.org.br/index.php/comunicacaoveredas/article/viewFile/ 5105/4723. Acesso em: 25 nov. 2011.

RAIMONDI, M.; WEBER, A. Os sentidos do país vizinho em jornais da fronteira Santana do Livramento (Brasil) e Rivera (Uruguai). Ideação (Online), 13: 1, 2011. 0. 81-108. Disponível em: file:///C:/Users/Andrea/Downloads/5276-20837-1-PB.pdf. Acesso em: 12 jul 2015.

RODRIGUEZ-ZUCOLILLO, C. Língua, nação e nacionalismo: um estudo sobre o guarani no Paraguai. 254f. Tese (Doutorado em Linguística). Instituto de Estudos da Linguagem. Universidade Estadual de Campinas, Campinas, 2000.

STEINBERGER-ELIAS, M.B. Jornalismo e imaginário internacional sobre o Mercosul. Revista Estudos de Jornalismo e mídia, v. 2, 2 sem, p. 63-73, 2005. Disponível em: http://www.periodicos.ufsc.br/index.php/jornalismo/article/view/2143. Acesso em: 24 jun. 2011.

STURZA, E. Línguas de fronteira: o desconhecido território das práticas linguísticas das fronteiras brasileiras. Ciência e Cultura, vol.57, n.3, p. 47-50. São Paulo, jul/set, $2005 . \quad$ Disponível em: http://cienciaecultura.bvs.br/pdf/cic/v57n2/a14v57n2.pdf. Acesso em: 13 jan. 2011.

STURZA, E. Línguas de fronteiras e política de línguas: uma história das idéias lingüísticas. 2006. $168 \mathrm{f}$. Tese (Doutorado em Linguística). Instituto de Estudos da Linguagem. Universidade Estadual de Campinas, Campinas, 2006.

STURZA, E; FERNANDES, I. A fronteira como novo lugar de representação do espanhol no Brasil. Revista Signo \& Seña, n. 20, p. 209- 227, 2009.

ZAJÍCOVÁ, L. Eı bilingüismo paraguayo. Madrid: Iberoamericana, 2009.

ZOPPI-FONTANA, M. O português do Brasil como língua transnacional. In: ZOPPYFONTANA(org). O português do Brasil como língua transnacional. Campinas: Ed. RG, 2009. p. 13-42. 
Para citar essa obra:

WEBER. A. F. Política de línguas, circulação de jornais e integração em cidades-gêmeas da fronteira. In: RUA [online]. ${ }^{\circ}$. 21. Volume 2, p. 381 - 399. ISSN 1413-2109. Junho/2015. Consultada no Portal Labeurb - Revista do Laboratório de Estudos Urbanos do Núcleo de Desenvolvimento da Criatividade.

http://www.labeurb.unicamp.br/rua/

Capa: Abrangência do jornal Diário da Fronteira, de Uruguaiana. Fonte: arquivo pessoal da autora.

\section{Laboratório de Estudos Urbanos - LABEURB}

Núcleo de Desenvolvimento da Criatividade - NUDECRI

Universidade Estadual de Campinas - UNICAMP

http://www.labeurb.unicamp.br/

Endereço:

LABEURB - LABORATÓRIO DE ESTUDOS URBANOS

UNICAMP/COCEN / NUDECRI

CAIXA POSTAL 6166

Campinas/SP - Brasil

CEP 13083-892

Fone/ Fax: (19) 3521-7900

Contato: http://www.labeurb.unicamp.br/contato 